\title{
Predictive Value of the GWTG Score to Heart Failure in South Indian Patients Admitted in ICU
}

\author{
Suresh Yerra ${ }^{1}$ Pragathi Gurram² \\ ${ }^{1}$ Department of Cardiology, Asian Institute of Gastroenterology- \\ Gachibowli, Hyderabad, Telangana, India \\ ${ }^{2}$ Department of Cardiology, Sunshine Hospital, Secunderabad, \\ Telangana, India
}

Ind J Car Dis Wom 2021;6:15-16.

Heart failure is one of the most common leading causes for death and it has a high morbidity which is a high burden to health care system. ${ }^{1}$ The Get With The Guidelines (GWTG) risk score which was established by Peterson et al in $2010^{2}$ is one of the scores used for risk stratification in heart failure and guides treatment options. Compared with many other risk calculators in heart failure, the GWTG risk score has small number of variables to be incorporated at the time of admission; so, it is widely applicable. However, there is sparse data available regarding the utility of this GWTG score in our population, especially South Indians. The original article on GWTG score applicability, published in the present issue, is aimed to see the applicability of predicted GWTG risk score of heart failure in the South Indians admitted to intensive cardiac care.

GWTG-HF risk score has several advantages and strengths; the variables which were used are small and can be collected at time of admission. It is quite cost effective and applicable for heart failure with both reduced and preserved ejection fraction as ejection fraction is not considered for risk score calculation. So, it can be widely applicable. Several other models of risk score prediction have more than 20 variables $^{3}$; they are not feasible and are difficult to use in routine clinical practice as compared with GWTG risk score. The present original article is relevant to publish because of its simplicity in its application.

In the original article as majority (70\%) of the patients come under group 2 (-Table $\mathbf{1}$ ), we think it is better to classify them under categories $2 \mathrm{a}$ and $2 \mathrm{~b}$, with category $2 \mathrm{a}$ having GWTG score 34 to 41 and 2b having GWTG score 42 to 50 so that GWTG-HF risk score can be used for better patient risk quantification, thus facilitating patient triage and encouraging the use of evidence-based therapy in the high-risk patients so that therapy can efficiently be used for high-risk patients (like group 2b than group 2a).
Address for correspondence

Suresh Yerra, MD, DM,

Asian Institute of

Gastroenterology-Gachibowli,

Hyderabad, Telangana, 500032,

India

(e-mail: yerrasuresh3@gmail.com).
As the GTWG score is applicable in both heart failure with reduced ejection fraction (HFrEF) and heart failure with preserved ejection fraction (HFpEF) we should also study whether this score is correlating with the in-hospital mortality and complications. This differentiation is not done in the study population which can help in the effective treatment strategy in such groups.

As more than $75 \%$ of the study group as categorized as ischemic cardiomyopathy (ICMP), in a newly diagnosed case of ICMP treatment strategy regarding viability studies and revascularization (immediate or after stabilization) should be better defined and GTWG score at baseline and post revascularization can be done; the in-hospital mortality and complications in both the groups should be compared.

In the DCMP group weather further diagnostic workup has be done such as cardiac imaging and endomyocardial biopsy (EMB) to diagnose inflammatory cardiomyopathy or infiltrative cardiomyopathy as the treatment strategy varies in such group along with the guideline-directed heart failure therapies.

In the original article brief mention about the available risk stratificationmodelssuchasAcuteDecomp-ensatedHeartFailure National Registry (ADHERE) study, ${ }^{4}$ OPTIMIZE-HF, Enhanced Feedback for Effective Cardiac Treatment (EFFECT), and Outcomes of a Prospective Trial of Intravenous Milrinone for Exacerbations of Chronic Heart Failure (OPTIME-CHF) mod$\mathrm{els}^{6,7}$ have been elucidated and the complexity and limitations of each model have been briefly mentioned. ${ }^{8}$

In conclusion the GWTG risk score is economical can be widely applicable, and it is readily available at the time of admission, with incorporate of limited variables and to triage, and to risk stratification which helps in implementing effective treatment strategies especially for the countries like India where resources are limited. We can divide the patients in to high-, moderate-, and low-risk groups and develop diagnostic and treatment strategies for better outcomes. Further studies
DOI https://doi.org/ $10.1055 / \mathrm{s}-0041-1728182$

published online April 9, 2021
This is an open access article published by Thieme under the terms of the Creative Commons Attribution-NonDerivative-NonCommercial-License, permitting copying and reproduction so long as the original work is given appropriate credit. Contents may not be used for commercial purposes, or adapted, remixed, transformed or built upon. (https://creativecommons.org/licenses/by-nc-nd/4.0/).

Thieme Medical and Scientific Publishers Pvt. Ltd. A-12, 2nd Floor, Sector 2, Noida-201301 UP, India 
Table 1 GWTG score table

\begin{tabular}{|l|l|l|l|l|}
\hline Group & Class of score & No. of patients & Percentage (\%) & Predicted mortality rate \\
\hline Group 1 & $0-33$ & 22 & 23 & $<1 \%$ \\
\hline Group 2 & $34-50$ & 68 & 70 & $1-5 \%$ \\
\hline Group 3 & $51-57$ & 7 & 7 & $5-10 \%$ \\
\hline Group 4 & $58-61$ & 0 & 0 & $10-15 \%$ \\
\hline Group 5 & $62-65$ & 0 & 0 & $15-20 \%$ \\
\hline Group 6 & $66-70$ & 0 & 0 & $20-30 \%$ \\
\hline Group 7 & $71-74$ & 0 & 0 & $30-40 \%$ \\
\hline Group 8 & $75-78$ & 0 & 0 & $40-50 \%$ \\
\hline Group 9 & $\geq 79$ & 0 & 0 & $>50 \%$ \\
\hline
\end{tabular}

are required incorporating large number of patients into study and to define the treatment strategies and to be incorporated in the management guidelines of heart failure patients.

\section{Conflict of Interest}

None declared.

\section{References}

1 Ambrosy AP, Fonarow GC, Butler J, et al. The global health and economic burden of hospitalizations for heart failure: lessons learned from hospitalized heart failure registries. J Am Coll Cardiol 2014;63(12):1123-1133

2 Peterson PN, Rumsfeld JS, Liang L, et al. American Heart Association Get With the Guidelines- Heart Failure Program. A validated risk score for in-hospital mortality in patientswith heart failure from the American Heart Association Get With the Guidelines program. CircCardiovascQual Outcomes 2010;3:25-32

3 Levy WC, Mozaffarian D, Linker DT, et al. The Seattle Heart Failure Model: prediction of survival in heart failure. Circulation 2006;113(11):1424-1433
4 Fonarow GC, Adams KF Jr, Abraham WT, Yancy CW, Boscardin WJ; ADHERE Scientific Advisory Committee, Study Group, and Investigators. Risk stratification for in-hospital mortality in acutely decompensated heart failure: classification and regression tree analysis. JAMA 2005;293(5):572-580

5 Abraham WT, Fonarow GC, Albert NM, et al. OPTIMIZE-HF Investigators and Coordinators. Predictors of in-hospital mortality in patients hospitalized for heart failure: insights from the Organized Program to Initiate Lifesaving Treatment in Hospitalized Patients with Heart Failure (OPTIMIZE-HF) J Am Coll Cardiol 2008;52(5):347-356

6 Felker GM, Leimberger JD, Califf RM, et al. Risk stratification after hospitalization for decompensated heart failure. J Card Fail 2004;10(6):460-466

7 Lee DS, Austin PC, Rouleau JL, Liu PP, Naimark D, Tu JV. Predicting mortality among patients hospitalized for heart failure: derivation and validation of a clinical model. JAMA 2003;290(19):2581-2587

8 Lyle M, Wan SH, Murphree D, et al. Predictive value of the Get With The Guidelines Heart Failure risk score in unselected cardiac intensive care unit patients. J Am Heart Assoc 2020;9(3):e012439 